\title{
Desenvolvimento motor de uma criança com síndrome de rubinstein-taybi submetida à intervenção fisioterapêutica
}

\author{
Motor development of a child with \\ rubinstein-taybi syndrome submitted to \\ physiotherapeutic intervention
}

\author{
Aila Pinheiro dos Santos ${ }^{1}$ (i) \\ Natali Costa da Silva ${ }^{2}$ (1) \\ Luana Karina de Almeida Nascimento 3 (1) \\ 1,2Centro Universitário Estácio de Sergipe (Aracaju). Sergipe, Brasil. aila.pinheiro23@gmail.com, nathaly.maze@hotmail.com \\ ${ }^{3}$ Autora para correspondência. Centro Universitário Estácio de Sergipe (Aracaju). Sergipe, Brasil. ft.luanakarina@gmail.com
}

\begin{abstract}
RESUMO | OBJETIVO: Analisar o comportamento motor de uma criança com Síndrome de RubinsteinTaybi sob estimulação fisioterapêutica. MÉTODO: Trata-se de um estudo de caso realizado com uma criança diagnosticada com SRT avaliada antes, durante e após sessões de fisioterapia através da Alberta Infant Motor Scale. O tratamento foi realizado no Centro de Integração Raio de Sol, em Aracaju/SE, onde as condutas foram aplicadas três vezes na semana, com duração de 50 minutos, e consistiram no treino das posturas neuroevolutivas. RESULTADOS: Verificou-se aumento nos escores de todas as posturas a partir da segunda avaliação, o que demonstra meIhora no desenvolvimento motor. CONCLUSÃO: A intervenção fisioterapêutica pode trazer benefícios no tratamento do atraso característico da SRT, ratificando a importância de novos estudos que investiguem o desempenho motor e o efeito da estimulação precoce em crianças com essa síndrome.
\end{abstract}

PALAVRAS-CHAVE: Deficiências do desenvolvimento. Fisioterapia. Síndrome de Rubinstein-Taybi. Saúde da criança. Anormalidades múltiplas.

\begin{abstract}
OBJECTIVE: Analyze the motor behavior of a child with Rubinstein-Taybi Syndrome under physical therapy stimulation. METHOD: This is a case study realized with a child diagnosed with SRT, evaluated before, during, and after physiotherapy sessions, through the Alberta Infant Motor Scale. The treatment was fulfilled at the Sun Ray Integration Center located in the Santa Maria neighborhood, in Aracaju / SE in which the ducts were applied three times a week for 50 minutes and consisted in the training of neuroevolutionary postures. RESULTS: It was verified an increase in all postures scores in the second and third evaluations, which shows an improvement in motor development. CONCLUSION: The Physiotherapeutic intervention can bring benefits to treat the characteristic delay of SRT, confirming the importance of further studies investigating motor performance and the effect of early stimulation in children with this syndrome.
\end{abstract}

DESCRIPTORS: Developmental Disabilities. Physical Therapy. Rubinstein-Taybi Syndrome. Child Health. Multiple Abnormalities. 


\section{Introdução}

A Síndrome de Rubinstein-Taybi (SRT) é uma condição genética que pode ser causada por eliminação ou mutação do gene CREBBP, localizado na região cromossómica 16p13.3, em que há codificação da proteína de ligação CREB, ou pela mutação no gene EP300 em 22q13, que codifica a proteína p300. Há poucos relatos atribuídos ao gene EP300 equivalente a uma porcentagem de $8 \%$ a $10 \%$ dos casos, já nas mutações no gene CREBBP ocorre comumente em cerca de $60 \%{ }^{1}$.

O gene CREBBP possui função de instruir a produção da proteína CREB, importante na regulação do crescimento e divisão celular, assim, quando uma cópia do gene CREBBP é eliminada ou sofre mutação, as células produzem metade do normal, limitando a função exercida por ela e interrompendo o desenvolvimento normal. O ocorrido é semelhante ao que acontece ao gene EP300, que instrui a produção da proteína específica que ajuda a controlar a atividade de outros genes. Ambos são importantes para o desenvolvimento antes e após o nascimento².

Apesar de ser uma síndrome rara, afetando 1 a cada 125.000 indivíduos, possui grande variabilidade clíni$\mathrm{ca}$, dificultando o estabelecimento de relações entre genótipo e fenótipo ${ }^{3}$. As alterações genéticas conferem ao paciente características clínicas próprias como microcefalia, ponte nasal alta, excesso de pelos e cabelo, polegares largos, duplicidade de falanges distais, hipotonia e frouxidão ligamentar, retardo de crescimento e da linguagem, deficiência intelectual e problemas comportamentais $s^{4-6}$, além de frequente presença de tumores malignos e benignos com prevalência significativa de meningiomas e pilomatricomas ${ }^{ }$.

Diversas síndromes possuem o retardo do desenvolvimento neuropsicomotor associado a elas, porém cada uma apresenta características e graus de comprometimento próprios, devendo-se levar em consideração o tipo de síndrome, fatores externos, como ambiente familiar e social, e fatores internos, como tipo de tônus e acuidade visual, levando a fisioterapia a determinar um prognóstico de acordo com um conjunto de fatores influentes e não somente com a causa da deficiênciå․
Estudos salientam que atrasos motores diagnosticados precocemente tendem a resultar num bom prognóstico, destacando a atuação da fisioterapia neuropediátrica que tem a finalidade de estimular o aprendizado motor induzindo o sistema nervoso a modificações práticas e dinâmicas, conduzindo à criança à independência funcional 1,10 . Não foram encontrados na literatura achados sobre a intervenção fisioterapêutica na respectiva síndrome, mesmo sabendo sua importância na correção dos atrasos motores. Sendo assim, esse estudo objetivou analisar o comportamento motor de uma criança com SRT sob intervenção fisioterapêutica.

\section{Metodologia}

Trata-se de um estudo de caso aprovado pelo Comitê de Ética e Pesquisa do Centro Universitário Estácio de Sergipe sob CAAE n 98140718.6.0000.8079 e parecer $\mathrm{n}^{\circ}$ 2.956.639, realizado com uma criança diagnosticada com SRT, que iniciou a pesquisa com idade corrigida de 7 meses e foi acompanhada desde sua inserção no serviço de Fisioterapia Pediátrica do Centro de Integração Raio de Sol, localizado no bairro Santa Maria, em Aracaju/SE.

Como instrumento de acompanhamento motor, utilizou-se a Alberta Infant Motor Scale (AIMS), onde a criança foi avaliada antes, durante e após sessões de fisioterapia pelo mesmo avaliador, obedecendo um intervalo de três meses entre as avaliações, totalizando um período de nove meses de acompanhamento. Os testes foram realizados através da observação livre da movimentação espontânea da criança, tendo como tempo médio de coleta 02 horas.

O tratamento consistiu em sessões de fisioterapia motora realizadas semanalmente três vezes, durante nove meses, com duração diária de 50 minutos, e consistiram no treino das posturas neuroevolutivas e estimulação das reações de equilíbrio e proteção, sendo utilizados recursos como rolos e bolas terapêuticas, skate e prancha de equilíbrio. 


\section{Resultados}

Constatou-se aumento nos escores das subescalas de todas as posturas neuroevolutivas na segunda avaliação, o que demonstra que após três meses de tratamento houve melhora no desenvolvimento motor e evoluindo com pontuações maiores nas terceira e quarta avaliações, conforme mostra o Gráfico 1. Percebeu-se, então, ganho importante nas aquisições de rolar, posturas extensoras em decúbito ventral, controle de tronco em sedestação e sustentação de peso em ortostase.

Gráfico 1. Representação gráfica dos escores das subescalas da AIMS

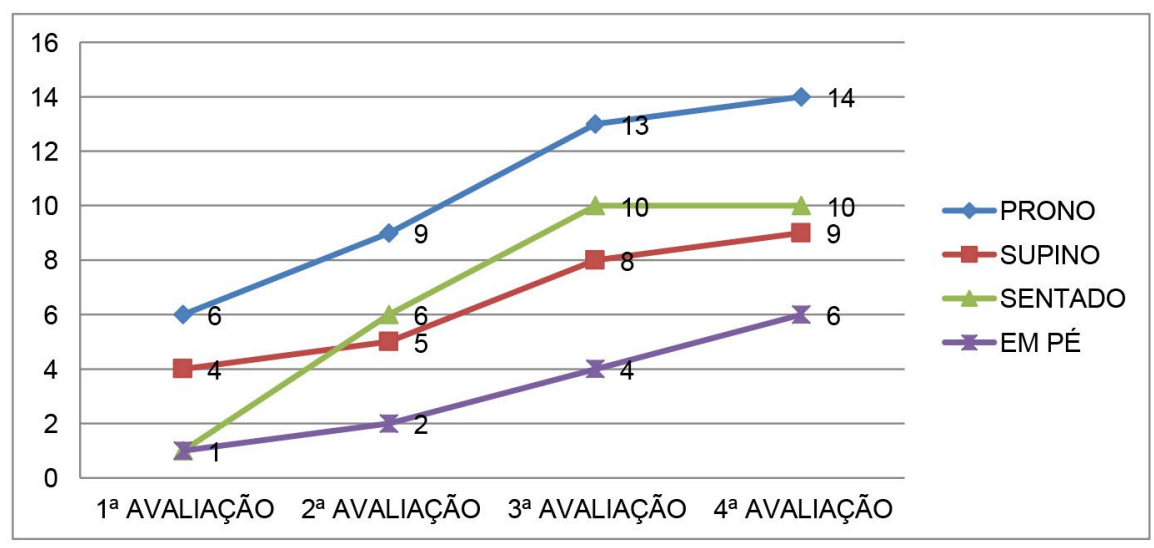

A Tabela 1 apresenta os valores dos escores brutos das quatro avaliações realizadas, onde os comportamentos motores demonstraram que mesmo com evoluções nos valores das subescalas gerando aumento consequente dos escores totais, a criança ainda apresenta atraso motor quando levada em consideração sua idade corrigida.

\begin{tabular}{cccc}
\multicolumn{4}{c}{ Tabela 1. Representação dos escores totais da AIMS } \\
& IDADE CORRIGIDA & ESCORE BRUTO & CLASSIFICAÇÃo \\
\hline $\mathbf{1}^{\text {a }}$ AVALIAÇÃO & 7 MESES & 12 & $<5 \%$ \\
\hline $\mathbf{2}^{\text {a }}$ AVALIAÇÃo & 10 MESES & 22 & $<5 \%$ \\
\hline $3^{\text {a }}$ AVALIAÇÃO & 12 MESES & 35 & $<5 \%$ \\
\hline $4^{\text {a }}$ AVALIAÇÃO & 16 MESES & 39 & $<5 \%$ \\
\hline AIMS: Alberta Infant Motor Scale & &
\end{tabular}

\section{Discussão}

Foi possível perceber a importância da intervenção fisioterapêutica na minimização dos atrasos motores decorrentes da SRT, constatando melhora e ganhos em todas as posturas neuroevolutivas.

No que concerne às posturas supinadas e pronadas, o estudo de Rodrigues et al. assemelha-se aos achados deste relato, ao verificarem melhora do desempenho motor em uma criança prematura após intervenção fisioterapêutica que consistia em estímulos psicomotores, técnicas de facilitação das habilidades motoras e estímulo das habilidades sensório-motoras e do tônus postural. Igualmente, avaliada através da AIMS, observaram-se ganhos na postura prono evidenciados pelo controle da cervical, apoio nos antebraços e mãos na tentativa de explorar o espaço que a rodeava, bem como o aprimoramento na posição supina em que a criança vivencia a rotação da cabeça em direção a algum estímulo e, assim, ativa sua percepção e lateralidade ${ }^{11}$. Outros estudos ${ }^{12,13}$ reforçam que à medida que a posição prono é aprimorada, a criança desenvolve habilidades em suporte de peso contra gravidade, favorecendo aprendizagem nas posturas em supino e sentado. 
Esse estudo demonstra ainda que à medida que a paciente aumentou o escore na postura prono, aumentou também o escore da postura sentada, passando a adquirir dez posturas na última aplicação. Pin et al. afirmam que a posição sentada está relacionada a outras aquisições motoras, principalmente à postura prono, devido ao recrutamento dos músculos da cabeça e do tronco superior, a fim de realizar extensão, facilitando assim a aquisição do controle de tronco em sedestação ${ }^{14}$. Vala menciona ainda que a média de idade do indivíduo com SRT aprender a sentar está entre 1 e 2 anos, o que ocorreu com a criança deste estudo. Ao final do tratamento com idade corrigida de 12 meses, mantinha a posição de sedestação sem apoio e realizava manipulação de objetos nessa postura ${ }^{15}$.

Os estímulos voltados à manipulação de objetos ativam musculaturas trabalhando articulações como ombro, cotovelo e punho, intervindo na mudança cinemática da mão, induzindo a criança a realizar alcance, linha média e dissociação dessas articulações ${ }^{16,17}$, além disso, o controle de tronco em sedestação gera estabilidade axial que fisiologicamente facilita as atividades apendiculares como as funções dos membros superiores na exploração, coordenação olho-mão e manipulação de objetos ${ }^{18,19}$. Esses resultados coincidem aos achados nesse estudo, pois a referida criança adquiriu a habilidade em manipular objetos e trazer a linha média, além de ter adquirido controle postural nas posições sentada e em pé com apoio.

Na postura em pé, a criança mostrou evolução realizando descarga de peso e mantendo-se em ortostase com apoio, no entanto, não houve aquisição da marcha. Sabe-se que a marcha é uma habilidade mais tardia e, de acordo com a AIMS, desenvolve-se entre 10 a 15 meses. Assim, ao final da intervenção a criança em estudo possuía 12 meses de idade corrigida, estando, portanto, no período fisiológico de desenvolvimento da marcha. No entanto, é imprescindível destacar que a influência da condição genética frente aos atrasos em etapas neuroevolutivas importantes, como sentar e engatinhar, contribui para o atraso no processo deambulatório, e, em indivíduos com SRT, esta aquisição ocorre por volta dos 4 anos de idade ${ }^{15}$.
De acordo com a Associação da Síndrome de Rubinstein-Taybi (ARTS), indivíduos com SRT possuem como características a adaptação a horários e tarefas rotineiras, sendo esse aspecto facilitador para o amadurecimento de suas atividades. Assim, levando-se em consideração que o processo interventivo na aquisição da aprendizagem motora requer repetição, torna-se importante a inserção dos treinos na rotina dessa criança até a criação de engrama, desenvolvimento das habilidades funcionais e aprimoramento das funções adquiridas ${ }^{20}$.

\section{Conclusão}

Nesse contexto, conclui-se que a intervenção fisioterapêutica na Síndrome de Rubinstein-Taybi poderá trazer benefícios no desenvolvimento das habilidades motoras neuroevolutivas. Apesar da relevância desse estudo, que se propõe disseminar o conhecimento científico nessa temática pouco explorada e conhecida, há limitações como o escasso acervo literário acerca do desempenho motor da criança com SRT, principalmente a respeito da estimulação precoce. Sugere-se, então, a realização de novos estudos que acompanhem o desenvolvimento global até a aquisição da marcha e que proponham novas intervenções terapêuticas, no sentido de minimizar os atrasos inerentes à síndrome.

\section{Contribuições das autoras}

Santos AP, Silva NC e Nascimento LKA foram responsáveis pela execução do projeto, coleta de dados, tabulação, análise dos dados e criação de tabelas e figuras. Santos AP, Silva NC foram responsáveis pela redação do texto e padronização das normas. Santos AP e Nascimento LKA são responsáveis pela revisão do texto e adição de partes significativas. Nascimento LKA orientou o projeto.

\section{Conflitos de interesses}

Nenhum conflito financeiro, legal ou político envolvendo terceiros (governo, empresas e fundações privadas, etc.) foi declarado para nenhum aspecto do trabalho submetido (incluindo, mas não se limitando a subvenções e financiamentos, participação em conselho consultivo, desenho de estudo, preparação de manuscrito, análise estatística, etc.). 


\section{Referências}

1. Hamilton MJ, Newbury-Ecob R, Holder-Espinasse M, Yau S, Lillis S, Hurst J, et al. Rubinstein-Taybi syndrome type 2: report of nine new cases that extend the phenotypic and genotypic spectrum. Clin Dysmorphol. 2016;25(4):135-45. https://doi.org/10.1097/ mcd.0000000000000143

2. MedlinePlus. CREBBP gene. CREB binding protein. [Internet]. Disponível em: https://medlineplus.gov/genetics/gene/crebbp/

3. López M, García-Oguiza A, Armstrong J, García-Cobaleda I, García-Miñaur S, Santos-Simarro F, et al. Rubinstein-Taybi 2 associated to novel EP300 mutations: deepening the clinical and genetic spectrum. BMC Med Genet. 2018;19(1):36. https://doi. org/10.1186/s12881-018-0548-2

4. Hennekam RMC. Rubinstein-Taybi syndrome. Eur J Hum Genet. 2006;14(9):981-5. https://doi.org/10.1038/sj.ejhg.5201594

5. Bartholdi D, Roelfsema JH, Papadia F, Breuning MH, Niedrist D, Hennekam RC, et al. Genetic heterogeneity in Rubinstein-Taybi syndrome: delineation of the phenotype of the first patients carrying mutations in EP300. J Med Genet. 2007;44(5):327-33. https://doi.org/10.1136/jmg.2006.046698

6. Reyes SJA, Paz SMRP, Palian PRC, Gutiérrez SÚM. Síndrome de Rubinstein-Taybi, atención odontoestomatológica a pacientes especiales: reporte de caso clínico. Rev. Odont mex [Internet]. 2016;20(3):202-7. Disponível em: https://www.medigraphic.com/ pdfs/odon/uo-2016/uo163h.pdf

7. Boot MV, Belzen MJ, Overbeek LI, Hijmering N, Mendeville M, Waisfisz Q, et al. Benign and malignant tumors in Rubinstein-Taybi syndrome. Am J Med Genet A. 2018;176(3):597-608. Citado em: PMID: 29359884

8. Corbetta D, DiMercurio A, Wiener RF, Connell JP, Clark M. How Perception and Action Fosters Exploration and Selection in Infant Skill Acquisition. Adv Child Dev Behav. 2018;55:1-29. https://doi. org/10.1016/bs.acdb.2018.04.001

9. Su YH, Jeng SF, Hsieh WS, Tu YK, Wu YT, Chen LC. Gross Motor Trajectories During the First Year of Life for Preterm Infants With Very Low Birth Weight. Phys Ther. 2017;97(3):365-73. https://doi. org/10.1093/ptj/pzx007

10. Mäenpää H, Häkkinen A, Sarajuuri A. Changes in Motor Development During a 4-Year Follow-up on Children With Univentricular Heart Defects. Pediatr Phys Ther. 2016;28(4):44651. https://doi.org/10.1097/pep.0000000000000298
11. Rodrigues JA, Mélo TR, Forti-Bellani CD, Castilho-Weinert LV. Acompanhamento de desenvolvimento motor de prematuro extremo com a escala alberta e intervenção pelo conceito bobath: relato de caso. Revista UNIANDRADE [Internet]. 2018;19(2):618. Disponível em: https://revista.uniandrade.br/index.php/ revistauniandrade/article/view/831/967

12. Dudek-Shriber L, Zelazny S. The effects of prone positioning on the quality and acquisition of developmental milestones in four-month-old infants. Pediatr Phys Ther. 2007;19(1):48-55. https://doi.org/10.1097/01.pep.0000234963.72945.b1

13. Martins TB, Silva CF, Rafael AD, Martinello M, Jonhston, C, Santos GM. Acquisition of posture control through of high postures in extremely preterm infants with diagnoses of Bronchopulmonary Dysplasia severe: case report. MTP\&Rehabjournal. 2016;14:1-4. https://doi.org/10.17784/ mtprehabjournal.2016.14.0285

14. Pin TW, Butler PB, Cheung H, Shum S. Relationship between segmental trunk control and gross motor development in typically developing infants aged from 4 to 12 months: a pilot study. BMC Pediatr. 2019;19:425. https://doi.org/10.1186/s12887-019-1791-1

15. Vala TM. Desenvolvimento motor de uma criança com síndrome de Rubinstein Taybi-estudo de caso [dissertação] [Internet]. São Carlos: UFSCAR; 2015. Disponível em: https:// repositorio.ufscar.br/bitstream/handle/ufscar/8707/DissTMV. pdf? sequence $=1$ \&isAllowed $=y$

16. Danielli CR, Farias BL, Santos DAPB, Neves FE, Tonetta MC, Gerzson LG, et al. Efeitos de um programa de intervenção motora precoce no desenvolvimento de bebês em um abrigo residencial. ConsSaúde. 2016;15(3):370-7. https://doi.org/10.5585/ conssaude.v15n3.6257

17. Bakker H, Graaf-Peters VB, Eykern LA, Otten B, Hadders-Algra M. Development of proximal arm muscle control during reaching in young infants: From variation to selection. Infant Behav Dev. 2010; 33(1):30-8. https://doi.org/10.1016/j.infbeh.2009.10.006

18. Harbourne RT, Dusing SC, Lobo MA, Westcott-McCoy S, Bovaird J, Sheridan S, et al. Sitting Together And Reaching To Play (START-Play): Protocol for a Multisite Randomized Controlled Efficacy Trial on Intervention for Infants With Neuromotor Disorders. Phys Ther. 2018;98(6):494-502. https://doi.org/10.1093/ ptj/pzy033

19. Yildiz A, Yildiz R, Elbasan B. Trunk Control in Children with Cerebral Palsy and its Association with Upper Extremity Functions. J Dev Phys Disabil. 2018;30:669-76. https://doi.org/10.1007/ $\underline{\text { s10882-018-9611-3 }}$

20. Associação Brasileira dos Familiares e Amigos dos Portadores da Síndrome de Rubinstein-Taybi - ARTS. [Internet]. São Paulo. Disponível em: www.artsbrasil.org.br 